\title{
Silicon-Boron Alloys as New Ultra-High Temperature Phase-Change Materials: Solid/Liquid State Interaction with the h-BN Composite
}

\author{
Wojciech Polkowski $^{1}$ (D) Natalia Sobczak ${ }^{1,2} \cdot$ Grzegorz Bruzda $^{1} \cdot$ Artur Kudyba $^{1} \cdot$ Rafal Nowak $^{1}$. \\ Adelajda Polkowska ${ }^{1} \cdot$ Izabela Krzak $^{1} \cdot$ Adam Tchórz $^{1}$ • Donatella Giuranno ${ }^{3}$
}

Received: 7 May 2019 / Accepted: 20 August 2019 / Published online: 7 September 2019

(C) The Author(s) 2019

\begin{abstract}
Silicon-boron alloys have been recently pointed out as novel ultra-high temperature phase change materials for applications in Latent Heat Thermal Energy Storage (LHTES) and conversion systems. One of the emerging challenges related to the development of such devices is a selection of refractories applicable to build a vessel for storing molten Si-B alloys at high temperatures and under consecutive melting/solidification conditions. Previously, it has been documented that hexagonal boron nitride ( $\mathrm{h}-\mathrm{BN}$ ) is the only one ceramic showing a non-wettability and limited reactivity with Si-B alloys at temperatures up to $1750^{\circ} \mathrm{C}$, what makes it a good candidate of the first selection for the predicted application. Nevertheless, pure h-BN shows a rather low mechanical strength that could affect a durability of the LHTES vessel. Therefore, the main purpose of this work was to examine high temperature behavior of commercial high strength $\mathrm{h}-\mathrm{BN}$ composite having a nominal composition of $\mathrm{h}-\mathrm{BN}-24 \mathrm{ZrO}_{2}-6 \mathrm{SiC}$ (vol.\%) in contact with a solid/liquid eutectic Si-3.2B alloy. Two types of sessile drop experiments were carried out: a step-contact heating up to $1750{ }^{\circ} \mathrm{C}$, and a thermocycling at $1300-1450{ }^{\circ} \mathrm{C}$ composed of 15 cycles of the alloy melting/solidification. The obtained results showed a lack of wettability in the examined system at temperatures up to $1750^{\circ} \mathrm{C}$. The Si-3.2B alloy presented good repeatability of melting/solidification temperatures in consecutive thermal cycles, which was not affected by the interaction with the h-BN composite. However, due to reactions taking place between the composite's components leading to structural degradation, it is not recommended to increase operational temperature of this material above $1450{ }^{\circ} \mathrm{C}$.
\end{abstract}

Keywords Silicon-boron alloys $\cdot$ Hexagonal boron nitride $\cdot$ Sessile drop method $\cdot$ Latent heat thermal energy storage . AMADEUS project

\section{Introduction}

Latent Heat Thermal Energy Storage (LHTES) plays an important role as a complementary technology for

Electronic supplementary material The online version of this article (https://doi.org/10.1007/s12633-019-00256-9) contains supplementary material, which is available to authorized users.

Wojciech Polkowski

wojciech.polkowski@iod.krakow.pl

1 Lukasiewicz Research Network - Foundry Research Institute, Zakopianska 73 Str., 30-418 Cracow, Poland

2 Lukasiewicz Research Network - Institute of Precision Mechanics, Duchnicka 3 Str., 01-796 Warsaw, Poland

3 National Research Council of Italy - Institute of Condensed Matter Chemistry and Technologies for Energy,

Via De Marini 6, 16149 Genova, Italy renewable energy sources (e.g. concentrated solar power systems) making them available during blackout periods $[1,2]$. The heart of every LHTES is a Phase Change Material (PCM) - a substance that is capable of storing and releasing large amounts of energy upon melting and solidification at a certain temperature range. Both organic and inorganic materials are under consideration to be used as PCMs. Regarding high-temperature applications, metals and alloys seem to be reasonable PCM candidates since they exhibit clear advantages over already applied molten salts or eutectic salts mixtures e.g. higher melting points, better thermal diffusivity, heat capacity and energy density. So far, research efforts in this field of using metals as PCMs have been mainly focused around aluminum, magnesium and zinc alloys having melting points $T_{m}<700{ }^{\circ} \mathrm{C}$ [3].

The main goal of European Commission founded AMADEUS Project (2017-2019) [4-6] is to combine extremely high latent heat values of silicon $(1800 \mathrm{~J} / \mathrm{g}$ 
at $\left.T_{m}=1414{ }^{\circ} \mathrm{C}\right)$ and boron $\left(4650 \mathrm{~J} / \mathrm{g}\right.$ at $T_{m}=$ $2076{ }^{\circ} \mathrm{C}$ )with a very high electrical power density of modern thermophotovoltaic (TPV) converter, in order to develop novel ultra-high temperature LHTES system. It is expected that using silicon and/or silicon-boron alloys as the PCMs should allow prominently increase capabilities of the state-of-the-art molten salt or metal-based LHTES devices, both in terms of operational temperatures and available energy density. Nevertheless, an increase of working temperature of Si-B alloy based LHTES system to $\sim 1400{ }^{\circ} \mathrm{C}$ brings a number of new materials science related challenges. One of them is significantly increased chemical reactivity of involved materials at such high temperatures. Consequently, a selection of proper refractories to build the PCM vessel that will ensure long-term reliability during consecutive melting/solidification of $\mathrm{Si}$ (or $\mathrm{Si}-\mathrm{B}$ alloys) becomes a demanding task.

In general, a lack of strong interaction (reflected by a lack of wetting and a low reactivity) between the PCM candidate and contacting ceramic material, is the most important requirement to be considered when choosing a material to build the high-temperature vessel. However, molten silicon has been already recognized as highly reactive towards most of ceramic materials. Due to high chemical affinity to $\mathrm{O}, \mathrm{N}$ and $\mathrm{C}$, direct contact of molten silicon with oxides, carbides and nitrides results in a reactive formation of interfacial products and a good wetting represented by contact angle values $\theta<90^{\circ}[7,8]$.

Recently [9], we have documented that hexagonal boron nitride (h-BN) is the only one ceramic showing a non-wetting behavior $\left(\theta>90^{\circ}\right)$ with molten $\mathrm{Si}$ at temperatures up to $1650{ }^{\circ} \mathrm{C}$, while the involved interaction is based on a dissolution/reprecipitation mechanism without a formation of any continuous product layers at the $\mathrm{Si} / \mathrm{h}$ $\mathrm{BN}$ interface. This behavior was subsequently confirmed in thermocycling experiments at a temperature interval of $1300-1450{ }^{\circ} \mathrm{C}$ including 15 consecutive cycles of melting/solidification [10]. Moreover, we also found, that the addition of boron to silicon (i.e. using silicon-boron alloys instead of pure $\mathrm{Si}$ ) further reduces the wettability with h-BN ceramic $[9,10]$. Due to a suppressed dissolution of h-BN in Si-B melt, near eutectic Si-B binary alloys exhibit very high contact angles $\left(\theta^{\sim} 1400{ }^{\circ} \mathrm{C}\right)$ at temperatures as high as $1750^{\circ} \mathrm{C}$.

Nevertheless, despite of the fact that h-BN shows good high temperature thermochemical compatibility with both silicon and silicon-boron alloys, it is characterized by a rather poor mechanical strength. Therefore, in order to enhance durability of the PCM vessel, high strength h-BN composite ought to be also taken into consideration as a candidate refractory material. Among various available $\mathrm{h}-\mathrm{BN}$ composites, a special attention is paid to these strengthened by $\mathrm{ZrO}_{2}$ and/or SiC particles.
The results of reported experimental works [12-14] confirmed that introduction of these ceramic reinforcements strongly enhances compressive strength (up to 10 times), fracture toughness, thermal shock resistance and oxidation resistance of the $\mathrm{h}-\mathrm{BN}$ matrix. The application area of commercially available $\mathrm{h}-\mathrm{BN}+\mathrm{ZrO}_{2}+\mathrm{SiC}$ composites includes e.g. components for high-temperature electric furnaces; insulators for plasma-jet furnaces, ion engines and PVD-ARC equipment; mechanical components, pipes and nozzles for liquid metal handling; molten metal and gas sensor components; casting components for precious metals, dental and other special alloys [15].

In our previous work [16], by using sessile drop experiment we have documented that a commercial h-BN$24 \mathrm{ZrO}_{2}-6 \mathrm{SiC}$ composite is much less wetted by molten $\mathrm{Si}$ at temperatures up to $1750{ }^{\circ} \mathrm{C}$, as compared to the pure h-BN counterpart. On the other hand, the results of structural characterization of solidified $\mathrm{Si} / \mathrm{h}-\mathrm{BN}$ composite couple have revealed that the wetting behavior is affected by the occurrence of chemical reactions between composite's components. These reactions lead to significant changes of microstructure, phase composition and surface morphology of the h-BN-based composite. Thus, in the view of practical applications of involved materials in ultra-high temperature LHTES units, it is important to deeply explore the course of structural and interfacial phenomena in Si-B alloy/(h-BN$24 \mathrm{ZrO}_{2}-6 \mathrm{SiC}$ ) system under predicted working conditions. In the present work we continue our research by examining for the first time the $\mathrm{Si}-3.2 \mathrm{~B}$ eutectic alloy/(h-BN- $24 \mathrm{ZrO}_{2}-$ $6 \mathrm{SiC}$ ) system in sessile drop experiments carried out in accordance to step-heating or thermocycling procedures. In this regard, our previous works on $\mathrm{Si} / \mathrm{h}-\mathrm{BN}$ [9, 10], Si-B/h$\mathrm{BN}$ [11] and $\mathrm{Si} / \mathrm{h}-\mathrm{BN}-24 \mathrm{ZrO} 2-6 \mathrm{SiC}$ [16] systems tested under the same conditions are treated as direct references. In order to avoid repeating certain information, more details on applied materials and testing procedures are available in our previous works and referenced in proper places in manuscript. This study is a step towards enhancing our understanding of reactivity and wettability of the molten eutectic Si-B alloy with the h-BN ceramic composite, and the performance of both materials under consecutive solid $\leftrightarrow$ liquid phase changes.

\section{Materials and Methods}

The materials investigated were eutectic Si-3.2B (wt\%) binary alloy produced by electric arc melting method (details on applied process are shown elsewhere [11]) and the commercially available hot-sintered h-BN-24Z $\mathrm{rO}_{2}-$ 6SiC composite (Henze HeBoSint O120, Germany). The $\mathrm{Si}-3.2 \mathrm{~B}$ alloy was produced from polycrystalline pure materials ( $\mathrm{Si}$ : $99.999 \%$; B: $99.9 \%$ as provided by Onyxmet, 
Poland). The Si-3.2B alloy/(h-BN-24ZrO $2-6 \mathrm{SiC})$ couples were subjected to sessile drop experiments performed by using experimental complex for investigation of high temperature capillarity phenomena, described elsewhere [17]. We used two types of sessile drop experiments (Fig. 1) to investigate performance properties of the selected PCM/refractory materials under an application determined conditions. The first one was designedto have a response about a maximum working temperature that could be applied for the $\mathrm{Si}-3.2 \mathrm{~B} /\left(\mathrm{h}-\mathrm{BN}-24 \mathrm{ZrO}_{2}-6 \mathrm{SiC}\right)$ couple placed in the heart of LHTES system. It is worth to emphasize that from the energy density point of view, the higher operational temperature could be achieved, the higher "energy efficiency" is received (i.e. the latent heat released at the melting point could be additionally enhanced be a sensible heat coming from an overheating of the melt). The step-heating experiment included 5 intervals at $1450{ }^{\circ} \mathrm{C} / 5$ min, $1550{ }^{\circ} \mathrm{C} / 5 \mathrm{~min}, 1650{ }^{\circ} \mathrm{C} / 5 \mathrm{~min}, 1700{ }^{\circ} \mathrm{C} / 5 \mathrm{~min}$ and $1750{ }^{\circ} \mathrm{C} / 10 \mathrm{~min}$ (Fig. 1a). The main purpose of this
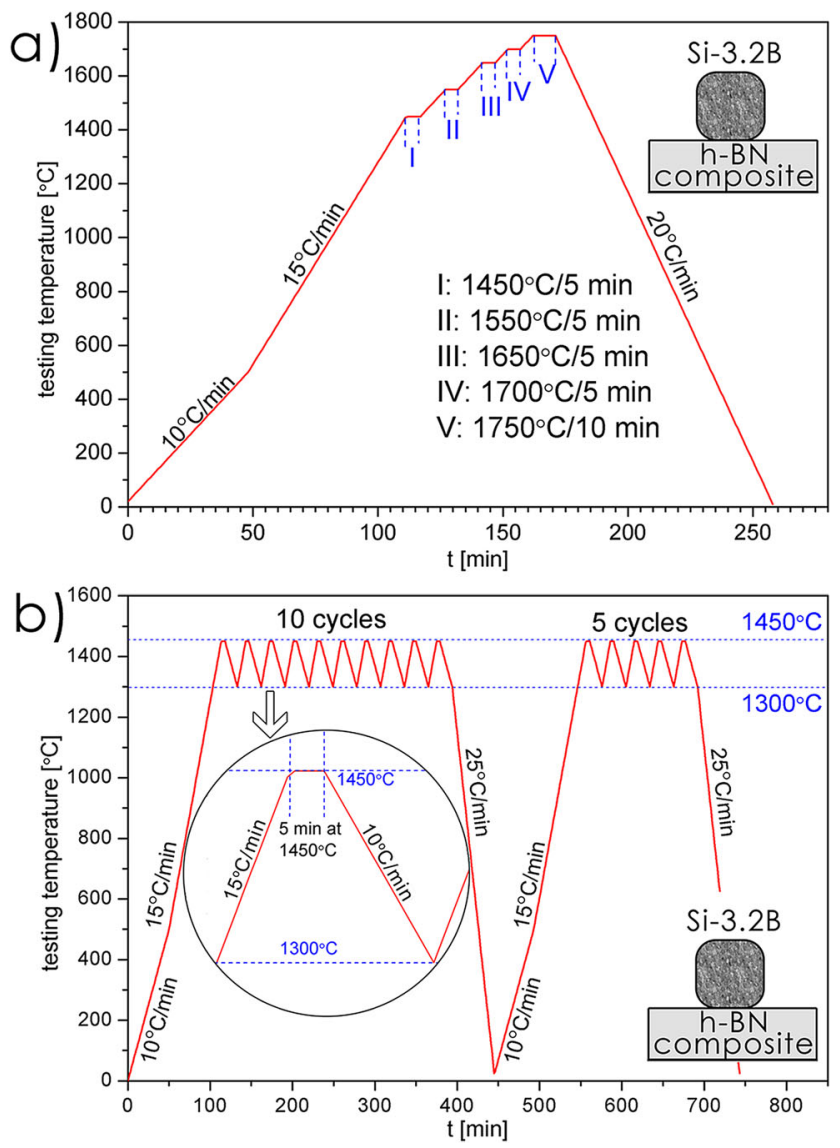

Fig. 1 Temperature profiles of high temperature sessile drop experiments of the Si-3.2B alloy/h-BN composite couples carried out by: a step-heating up to $1750{ }^{\circ} \mathrm{C}$ with five intervals (a); a thermocycling including 15 heating/cooling cycles between 1300 and $1450{ }^{\circ} \mathrm{C}$ with the intermediate cooling to room temperature after $10^{\text {th }}$ cycle test was to examine the effect of testing temperature on wetting characteristics, and to establish applicability limits of selected materials. The same temperature profile was applied in our previous works $[9,11,16]$. The second type of the sessile drop test (Fig. 1b) was performed in order to assess the performance of a system upon cycling melting/solidification processes. For this reason, the selected PCM candidate/h-BN composite couple was subjected to a sessile drop experiment containing 15 cycles of heating/cooling between $1300-1450{ }^{\circ} \mathrm{C}$, with an intermediate cooling down to room temperature after 10 cycles. The upper and lower temperature limits were selected in order to cover melting and solidification ranges of the Si-3.2B alloy. According to the Si-B binary phase diagram a theoretical melting point of the eutectic alloy is $T_{m}=1385{ }^{\circ} \mathrm{C}$. However, by taking into account the overcooling effect the lower temperature limit was set at $T=1300{ }^{\circ} \mathrm{C}$. The heating/cooling rates used upon the thermocycling experiment were relatively higher than that predicted in the final application, in order to examine the materials' behavior under "forced" conditions that should accelerate their potential degradation. During these tests, the temperatures of specific events (melting, solidification) as well as contact angle values were recorded. The same thermocyclic procedure was applied also in our previous work [10]. It should be highlighted that during both sessile drop experiments, the same procedure for the preparation of the high temperature chamber was applied as follows. After placing a metal/substrate couple inside the chamber, gases were evacuated using Scroll and turbo-molecular pumps. When a pressure inside the chamber reached the value of about $1 \times 10^{-6}$ mbar, heating was started following one of the pre-selected temperature profile. At temperature of $800{ }^{\circ} \mathrm{C}$, the inert gas (static argon, $p=850-900$ mbar) was introduced to the chamber in order to suppress the evaporation of the silicon-boron alloy.

After the high temperature tests, the solidified couples were removed from the chamber and subjected to a structural characterization by using the Carl Zeiss Axio Observer ZM10 Light Microscope (LM) and FEI Scios ${ }^{T M}$ Field Emission Gun Scanning Electron Microscope (FEG SEM) coupled with Energy Dispersive X-Ray Spectroscopy (EDS). The examinations were performed both on crosssectioned samples. The sessile drop couples were also nondestructively inspected by X-ray Computed Tomography (CT) technique. The GE Phoenix Nanotom M CT device operating under voltage of $100 \mathrm{kV}$, current of $65 \mu \mathrm{A}$, exposure time of $500 \mathrm{~ms}$ and voxel size of $8.0 \mu \mathrm{m}$ was used for the acquisition of X-ray images. A digital reconstruction of the scanned object was performed by using Datos- $\mathrm{x}$ reconstruction and VGStudio Max 2.0 commercial software. 


\section{Results and Discussion}

\subsection{Characterization of Materials Structure in Initial Condition (Before Experiments)}

The Si-3.2B alloy produced by electric arc melting method was characterized by a complex multiphase structure (Fig. 2a) with a matrix composed of a mixture of $\mathrm{Si}(\mathrm{B})$ solid solution and $\mathrm{Si}(\mathrm{B})+\mathrm{SiB}_{3}$ eutectic. Additionally, a few randomly distributed particles of silicon tertraboride $\left(\mathrm{SiB}_{4}\right)$ and boron carbide $\left(\mathrm{B}_{4} \mathrm{C}\right)$ were also detected based on the results of detailed SEM/EDS analyses. Although it is well known that EDS exhibits a strong limitation in quantifying light elements like carbon and boron, we used it to examine a local chemical composition inside these particles. The results revealed that the $\mathrm{B} / \mathrm{Si}$ atomic ratio measured in different sites of the grey particles was $4.11 \pm 0.13$, while the $\mathrm{B} / \mathrm{C}$ atomic ratio for the black ones was $4.07 \pm 0.09$, thus corresponding to $\mathrm{SiB}_{4}$ and $\mathrm{B}_{4} \mathrm{C}$ phases respectively. Despite of the fact that the $\mathrm{SiB}_{4}$ is not marked in the widely accepted form of the Si-B binary equilibrium phase diagram [18], its existence has been documented in more recent experimental works, e.g. [19, 20]. Since the $\mathrm{SiB}_{4}$ phase exhibits a lower thermal stability as compared to $\mathrm{SiB}_{3}$ and $\mathrm{SiB}_{6}$ borides, its presence should be justified in terms of strongly nonequilibrium conditions of the solidification during applied arc-melting processing. The existence of boron carbide particles should be associated with a carbon contamination coming from batch materials. Structural characterization of the h-BN-composite substrate shows that the $\mathrm{ZrO}_{2}$ (bright) and $\mathrm{SiC}$ (grey) particles having an irregular shape and size up to $\sim 10 \mu \mathrm{m}$ were homogeneously distributed in the h-BN matrix (Fig. 2b). More details on the investigated materials are shown in our previous works $[11,16]$.

\subsection{Wettability in Si-3.2B Alloy/(h-BN+SiC+ZrO2) System}

\subsubsection{The Step-Heating Experiment (up to $1750^{\circ} \mathrm{C}$ )}

The fast-forward video recorded during the step-heating test is available as the Electronic Supplementary Material 1, while the wetting kinetics curve (contact angle $\theta$ vs. t) calculated from captured images is presented in Fig. 3.

The contact angle values were very high in the whole examined temperature range, but they slightly decreased from $\theta 1450=147^{\circ}$ to $\theta 1750=134^{\circ}$, with increasing testing temperature from 1450 to $1750{ }^{\circ} \mathrm{C}$, respectively. What should be noted is that the Si-3.2B alloy shows a lower wettability (reflected by prominently higher contact angles) with the h-BN composite, than the pure silicon

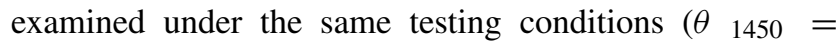
$132^{\circ}$ to $\theta 1750=110^{\circ}$ ) [16]. This finding confirms the previously observed effect of boron addition to silicon on suppressing high temperature wettability through hindering a dissolution of h-BN matrix in the molten alloy [11]. Interestingly, the wetting behavior of the $\mathrm{Si}-3.2 \mathrm{~B}$ alloy/h$\mathrm{BN}$ composite couple during cooling from $1750{ }^{\circ} \mathrm{C}$ is also quite different than that of previously examined $\mathrm{Si} / \mathrm{h}$ BN composite couple. As opposite to the pure silicon counterpart, the Si-3.2B alloy showed a lack of "dewetting movement" (i.e. a lack of visible increase of contact angle) upon cooling down from $1750{ }^{\circ} \mathrm{C}$. This finding gives a one more evidence that addition of boron to silicon stabilizes the investigated system and allows achieving thermodynamic equilibrium between the liquid material and the h-BN-based ceramic.

\subsubsection{Thermocycling Experiment - Consecutive Melting/Solidification Between $1300-1450^{\circ} \mathrm{C}$}

The fast-forward video recorded during the thermocycling experiment is available as the Electronic Supplementary Material 2. Figure 4 summarizes results obtained during the thermocycling experiment, i.e. it gives information about cyclic behavior of the $\mathrm{Si}-3.2 \mathrm{~B}$ alloy upon contact heating/cooling with the h-BN composite in terms of the wettability (a "stability" of contact angle) and melting/solidification range in each consecutive cycle. A set of real-time images of the $\mathrm{Si}-3.2 \mathrm{~B} /\left(\mathrm{h}-\mathrm{BN}-24 \mathrm{ZrO}_{2}-\right.$ $6 \mathrm{SiC}$ )substrate taken after $5 \mathrm{~min}$ holding at $1450{ }^{\circ} \mathrm{C}$ in each thermal cycle, is presented in Fig. 4a, while observed temperatures of specific events (melting, solidification) and contact angle values are shown in Fig. $4 \mathrm{~b}$ and c,

Fig. 2 SEM images showing a microstructure of the investigated materials: the $\mathrm{Si}-$ 3.2B eutectic alloy (a) and the commercial h-BN-24ZrO $2-6 \mathrm{SiC}$ composite (b)
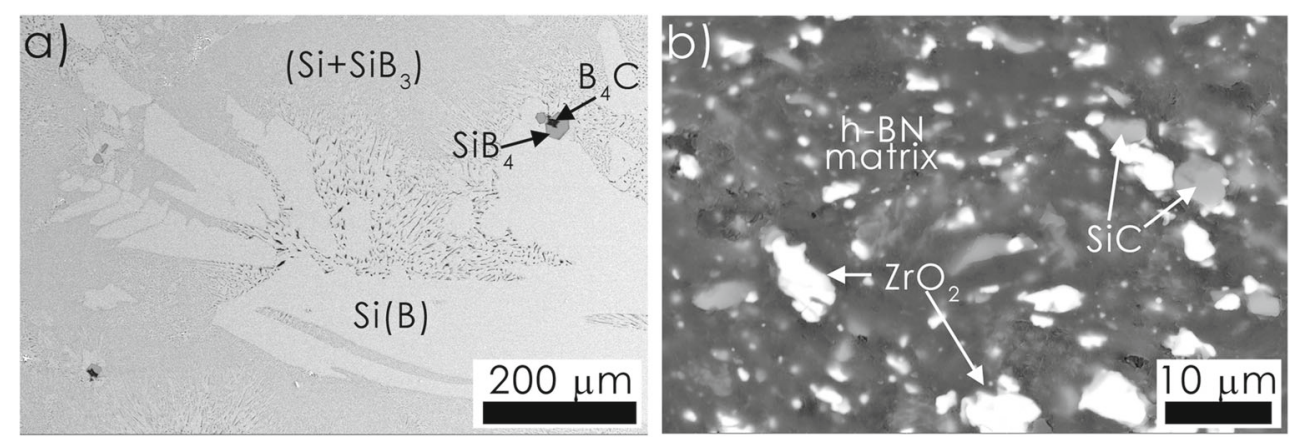
Fig. 3 The wetting kinetics curve (showing a change of contact angle $\theta$ vs. testing time) obtained for Si-3.2B alloy subjected to step-heating up to $1750{ }^{\circ} \mathrm{C}$ in contact with the h-BN composite substrate (data for pure $\mathrm{Si}$ are taken from ref. [16]). Please note that contact angle values at $1750{ }^{\circ} \mathrm{C} / 5 \mathrm{~min}$ were characterized by high uncertainty due to a presence of some solid state particles in the vicinity of triple line
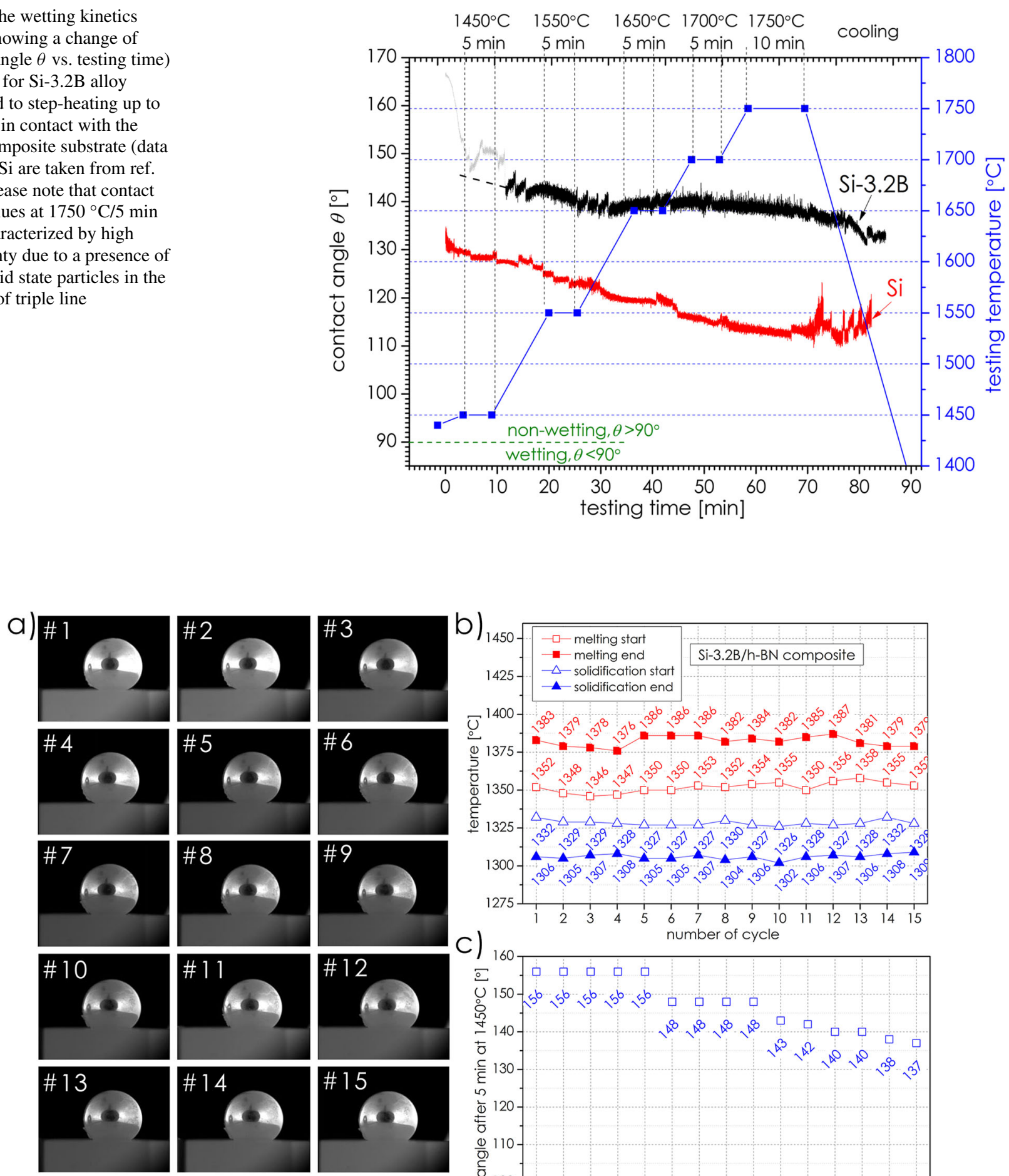

\# 15
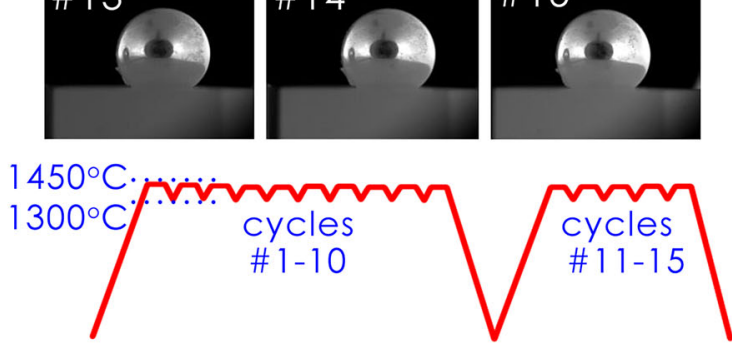

Fig. 4 Images of the $\mathrm{Si}-3.2 \mathrm{~B}$ drop/(h-BN- $\left.24 \mathrm{ZrO}_{2}-6 \mathrm{SiC}\right)$ substrate insitu recorded after 5 minutes holding at $1450{ }^{\circ} \mathrm{C}$ in each cycle (a). The recorded temperature ranges of melting and solidification of the

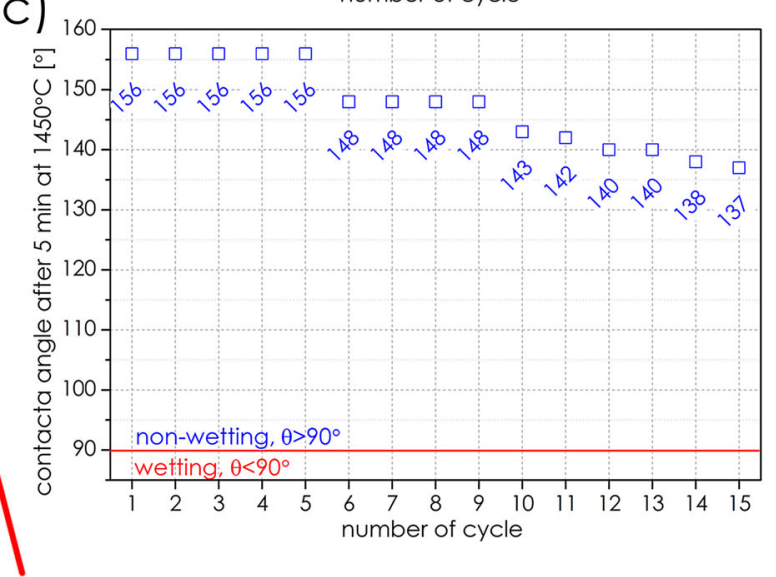

Si-3.2B alloy (b). The average contact angle $\theta$ values calculated for the $\mathrm{Si} /\left(\mathrm{h}-\mathrm{BN}-24 \mathrm{ZrO}_{2}-6 \mathrm{SiC}\right)$ couple during consecutive cycles (after 5 min holding at $\left.14500^{\circ} \mathrm{C}\right)(\mathbf{c})$ 
respectively. It is documented that the $\mathrm{Si}-3.2 \mathrm{~B}$ alloy completely melts at temperature around $1384 \pm 8{ }^{\circ} \mathrm{C}$ (average from 15 cycles) (Fig. 4b), which is very close to theoretical melting point of eutectic composition $\left(T_{m}=1385{ }^{\circ} \mathrm{C}\right)$ described by Olesinski and Abbaschian in the Si-B binary phase diagram [18]. During cooling down from $1450{ }^{\circ} \mathrm{C}$ at $10{ }^{\circ} \mathrm{C} / \mathrm{min}$ the full solidification of the Si-3.2B drop was obtained at temperature of $1306 \pm 2^{\circ} \mathrm{C}$ (average from 15 cycles), thus giving the undercooling of $\Delta T=78^{\circ} \mathrm{C}$. This value is slightly higher than that of pure $\operatorname{Si}\left(\Delta T=70^{\circ} \mathrm{C}\right)$ previously examined under the same testing conditions [10]. Generally, the melting/solidification behavior of the Si-3.2B alloy was characterized by a good repeatability in consecutive thermal cycles, as well as it seems to be not affected by interaction with the h-BN composite. The average contact angle recorded after 5 min holding at $1450{ }^{\circ} \mathrm{C}$ in each consecutive cycles presented very high values, significantly above the non-wetting regime $\left(\theta>90^{\circ}\right)$ (Fig. 4c). Nevertheless, a slight decrease of contact angle from $\theta=156^{\circ}$ (recorded in the $1^{s t}-5^{t h}$ cycles) to $\theta=137^{\circ}$ after the $15^{t h}$ cycle should be related to an in-situ modification of the h-BN composite's surface that took place during the high temperature exposure. It should be noted that this behavior was strikingly different than that observed during testing of pure Si/h-BN couple under the same conditions [10]. In that case, the interaction was dominated by a cyclic dissolution of h-BN ceramic in molten $\mathrm{Si}$ at $1450^{\circ} \mathrm{C}$ followed by a reprecipitation of h-BN platelets during cooling to $1300^{\circ} \mathrm{C}$.
Consequently, the solid/solid interface of the Si/h-BN couple was gradually modified leading to increase of contact angle in consecutive cycles and a spontaneous detachment of Si drop from the h-BN substrate. A lack of this phenomenon between presently examined materials, confirms that addition of boron to silicon decreases a dissolution of h-BN ceramic in molten alloy, and thus it also hinders the reprecipitation of h-BN platelets during cooling of B-, Cand $\mathrm{N}$-saturated melt.

\subsection{Structural Characterization of Si-3.2B Alloy/(h-BN+SiC $\left.+\mathrm{ZrO}_{2}\right)$ Sessile Drop Couples After High Temperature Tests}

A comparison of microscopic images taken from crosssectioned Si-3.2B alloy/h-BN-24ZrO $2-6 \mathrm{SiC}$ ) couples clearly points towards a very strong impact of testing temperature on the course of involved interfacial phenomena. In the case of the sample subjected to the step-heating experiment at temperatures up to $1750{ }^{\circ} \mathrm{C}$, the results of combined LM and SEM/EDS analyses (Fig. 5) revealed a substantial alteration of materials structure as well as the formation of interfacial products. Based on the results of detailed local EDS chemical composition analyses the following structural features were recognized:

1. a matrix of the alloy composed of the mixture of $\mathrm{Si}(\mathrm{B})$ solid solution and $\left(\mathrm{Si}+\mathrm{SiB}_{3}\right)$ eutectic (Fig. $\left.5 b\right)$;
Fig. 5 The results of LM and SEM/EDS examinations of the cross-sectioned Si-3.2B alloy/h-BN composite couple after the step-heating experiment up to $17500^{\circ} \mathrm{C}$ : a general view of the solidified Si-3.2B alloy (a); a microstructure of solidified drop showing $\mathrm{Si}+\mathrm{SiB}_{3}$ eutectic features (b); two types of silicon borides $\left(\mathrm{SiB}_{3}\right.$ and $\left.\mathrm{SiB}_{6}\right)$ distributed in the close vicinity of drop surface and at the alloy/ceramic interface; $\mathbf{c}$ a discontinuous bicomponent product layer $\left(\mathrm{B}_{4} \mathrm{C}+\mathrm{SiC}\right)$ formed at the $\mathrm{Si}-3.2 \mathrm{~B}$ alloy/h-BN composite interface $(\mathbf{d})$
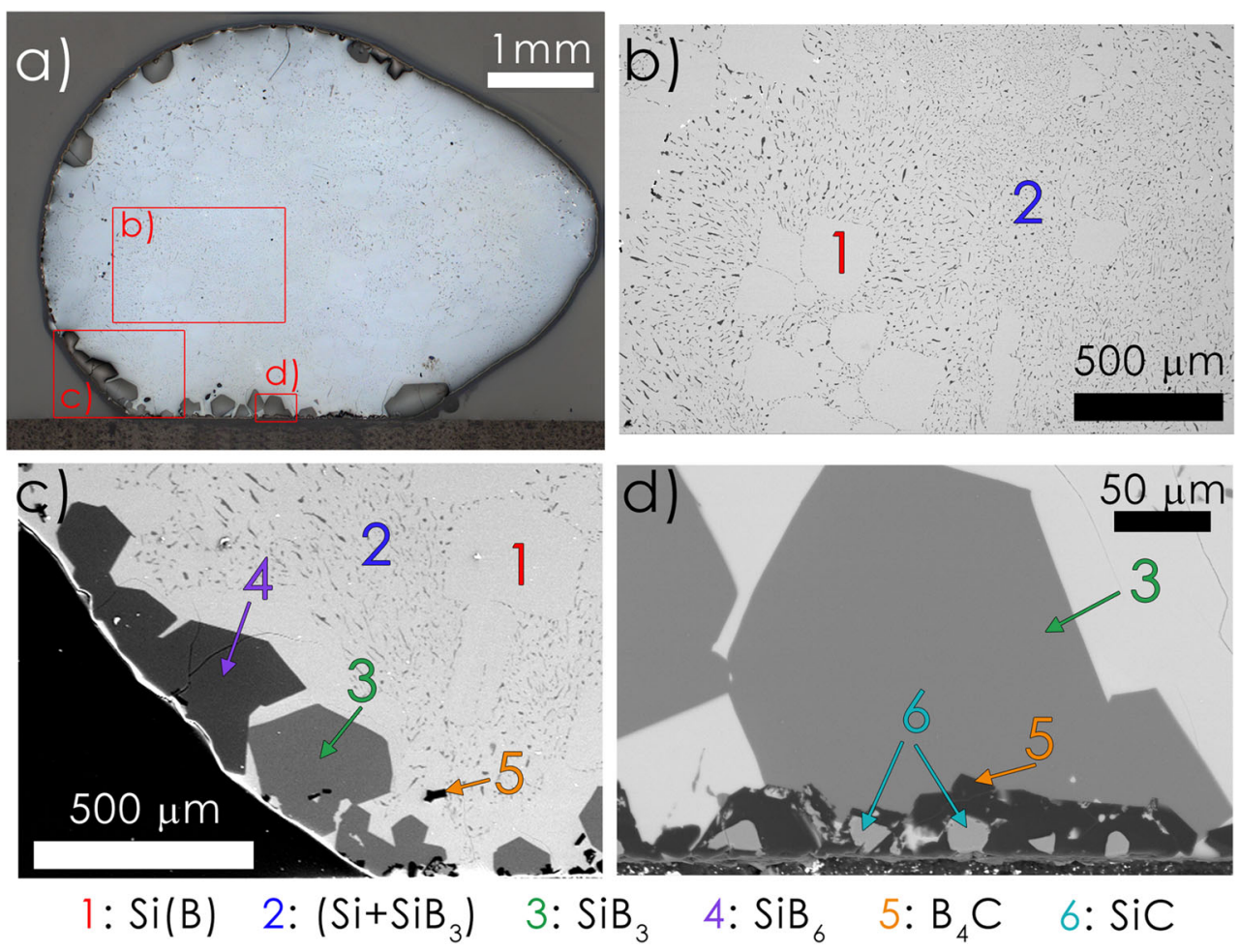

1: $\mathrm{Si}(\mathrm{B}) \quad 2:\left(\mathrm{Si}+\mathrm{SiB}_{3}\right) \quad 3: \mathrm{SiB}_{3} \quad 4: \mathrm{SiB}_{6} \quad 5: \mathrm{B}_{4} \mathrm{C} \quad$ 6: $\mathrm{SiC}$ 
2. two types of silicon borides $\left(\mathrm{SiB}_{3}\right.$ and $\left.\mathrm{SiB}_{6}\right)$ (Fig. 5c) in the form of relatively large crystals distributed in the close vicinity of drop surface and the alloy/ceramic interface (a lack of the meta-stable $\mathrm{SiB}_{4}$ phase observed in the initial material proves that during the ultra hightemperature exposure the alloy changed its structure towards a more equilibrium state);

3. a dense, but discontinuous bicomponent product layer formed at the $\mathrm{Si}-3.2 \mathrm{~B}$ alloy/h-BN composite interface. The product layer was composed of $\mathrm{B}_{4} \mathrm{C}$ and $\mathrm{SiC}$ crystals (Fig. 5d).

A large fraction of the $\left(\mathrm{Si}+\mathrm{SiB}_{3}\right)$ eutectic mixture in the structure of solidified Si-3.2B drop presents a good agreement with its theoretical equilibrium composition. A distribution of silicon borides at gas/liquid and liquid/solid interfaces of the solidified couple crystals suggests that they were produced during cooling by a nucleation and growth. On the other hand, the interfacial product layer $\left(\mathrm{B}_{4} \mathrm{C}+\mathrm{SiC}\right)$ was most probably formed due to the dissolution of h-BN matrix in the molten alloy assisted by a thermal decomposition of primary $\mathrm{SiC}$ particles.

Analogously as in our previous experimental work [16], $\mathrm{SiC}$ particles embedded in the near surface area of the
h-BN body are decomposed $(\mathrm{SiC} \rightarrow \mathrm{Si}+\mathrm{C})$ in contact with the liquid Si-B alloy. Consequently, "free carbon" is dissolved in the liquid Si-B alloy, while its amount increases with increasing testing temperature. During cooling B- and C- and N- saturated melt down from from $1750{ }^{\circ} \mathrm{C}$, both $\mathrm{B}_{4} \mathrm{C}$ and $\mathrm{SiC}$ particles are nucleated and grown at the interface on the drop side via a dissolution/reprecipitation mechanism. In this regard, the main difference between the previously examined pure silicon [16] and presently tested $\mathrm{Si}-3.2 \mathrm{~B}$ alloy is the phase composition of the discontinuous interfacial product layer. In the former case it was a single-phase $\mathrm{SiC}$, while addition of boron in the latter one allows producing bicomponent layer made of $\mathrm{SiC}$ and $\mathrm{B}_{4} \mathrm{C}$ precipitates. Additionally, in order to provide a general view on distribution and morphology of structural components inside the solidified $\mathrm{Si}-3.2 \mathrm{~B}$ alloy/(h-BN-24ZrO $2-6 \mathrm{SiC})$ sessile drop couple, non-destructive $\mathrm{CT}$ inspections were carried out before cutting the samples. Exemplary CT images of the couple are shown in Fig. 6, while a video showing the full 3D-CT scan is available as the Electronic Supplementary Material 3.

On contrary, the LM and SEM inspections of the cross-sectioned Si-3.2B alloy/h-BN composite couple after the thermocycling experiment between $1300-1450{ }^{\circ} \mathrm{C}$
Fig. 6 The results of CT examinations of the $\mathrm{Si}-3.2 \mathrm{~B}$ alloy/h-BN composite solidified couple after the step-heating experiment: a general view (a); the interface area showing a discontinuous layer composed of $\mathrm{B}_{4} \mathrm{C}$ and $\mathrm{SiC}$ crystals (b); a distribution of borides and carbides in the vicinity of drop surface and at the drop/substrate interface $(\mathbf{c}-\mathbf{e})$
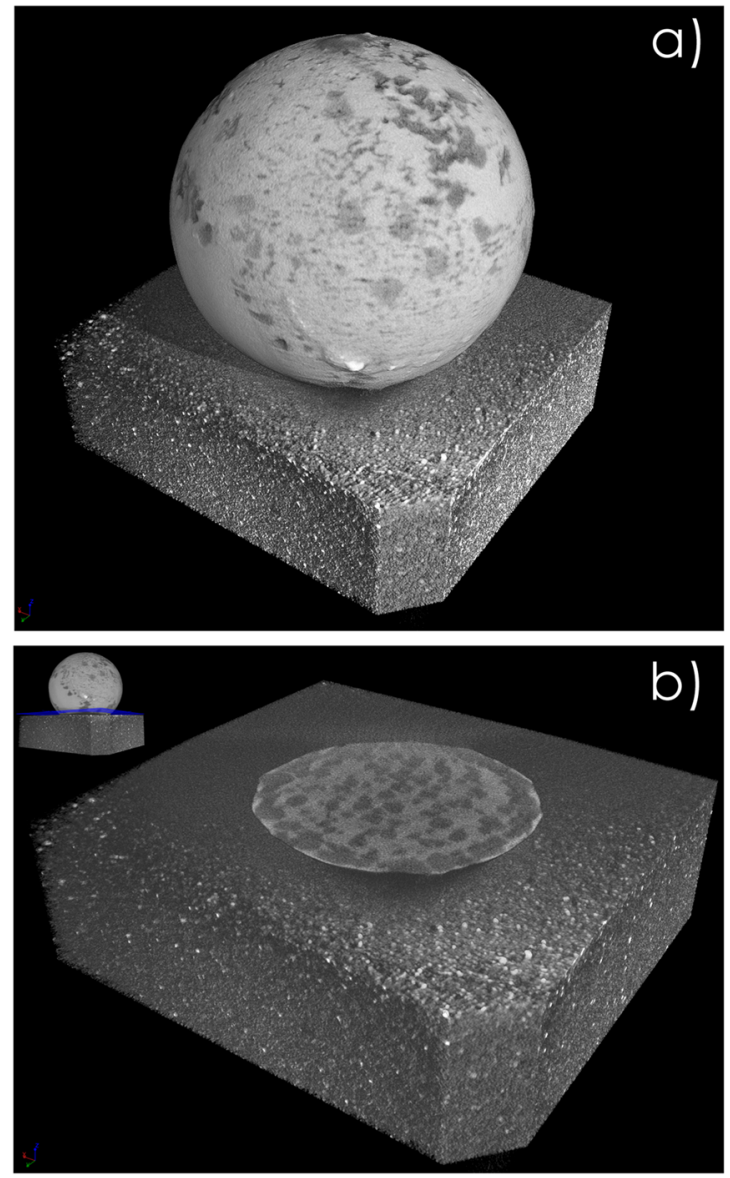
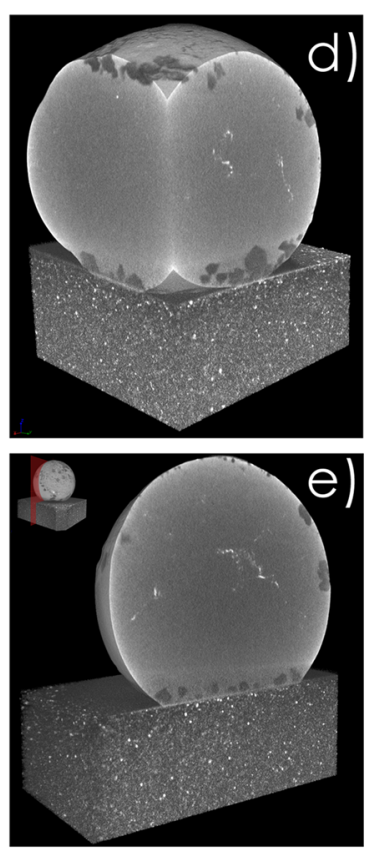
revealed a much less extensive structural evolution (Fig. 7a). Although, the internal structure of the Si-3.2B alloy (Fig. 7b) seems to be only slightly different than that obtained in the material cooled down from $1750{ }^{\circ} \mathrm{C}$, interface areas were visibly disparate. First of all, the presence of neither silicon borides distributed in the close vicinity of drop surface nor the $\left(\mathrm{B}_{4} \mathrm{C}+\mathrm{SiC}\right)$ product layer at the alloy/ceramic interface, was observed. In fact, only a few small SiC crystals were detected at the drop/substrate interface (Fig. 7c). This difference between examined samples can be justified by the following interconnected reasons:

1. a strong effect of temperature on solubility of boron in silicon. According to the Si-B binary phase diagram [18], the solubility limits at 1450 and $1750{ }^{\circ} \mathrm{C}$ are 5.9 and $14.16 \mathrm{wt} \%$ (14 and 30 at.\%), respectively. Thus, it is reasonable to conclude that at temperature as high as $1750{ }^{\circ} \mathrm{C}$, a much more boron (needed for the formation of interfacial borides) is dissolved in molten alloy from the contacting h-BN based ceramic.

2. a limited interaction between the molten Si-B alloy and the composite at temperatures below $1450{ }^{\circ} \mathrm{C}$ (i.e. a hindered dissolution of h-BN matrix and decomposition of primary $\mathrm{SiC}$ crystals).

Above mentioned findings are in line with the results of structural characterization of the cross-sectioned (h$\left.\mathrm{BN}+\mathrm{SiC}+\mathrm{ZrO}_{2}\right)$ substrates after the high-temperature tests (Fig. 8). A clearly visible Zone of Internal Reaction (ZIR) may be distinguished even in low-magnification images (Fig. 8a and d). What should be noted is that the ZIR is much deeper in the case of the sample tested at higher temperatures (up to $1450{ }^{\circ} \mathrm{C}$ ). The same substrate appearance characterized by an existence of highly porous $\mathrm{SiC}$-free outer part and reacted/unreacted transition area was observed in our previous work on the $\mathrm{Si} / \mathrm{h}-\mathrm{BN}$ composite system tested under the same conditions [16]. As previously, the structural evolution of the examined h-BNbased composite upon the high temperature exposure was dominated by reactions taking place as follows:

1. melting and evaporation of native $\mathrm{B}_{2} \mathrm{O}_{3}$ boron oxide that is introduced during sintering of the h-BN composite. $\mathrm{B}_{2} \mathrm{O}_{3}$ melts at $T_{m}=452{ }^{\circ} \mathrm{C}$ [21] and under non-oxidizing conditions it quickly evaporates (under atmospheric pressure it starts at $1227^{\circ} \mathrm{C}$, while under vacuum the evaporation takes place at much lower temperatures) [22]. The existence of liquid boron oxide supports a decomposition of $\mathrm{SiC}$ particles through the following reaction [22]:

$$
\mathrm{SiC}+\mathrm{B}_{2} \mathrm{O}_{3(l)} \rightarrow \mathrm{B}_{2} \mathrm{O}_{2} \uparrow+\mathrm{CO} \uparrow+\mathrm{Si}
$$

2. reactions between the composite components (h-BN and $\mathrm{ZrO}_{2}$ ) facilitated by a thermal destabilization of primary $\mathrm{SiC}$ phase in contact with liquid boron oxide and/or Si-B melt. As it was theoretically and experimentally documented by Yan et al. [23], at temperature above $\sim 1480{ }^{\circ} \mathrm{C}$, h-BN reacts with zirconia and carbon (coming from a destabilization of $\mathrm{SiC}$ ) to form zirconium diboride:

$$
2 \mathrm{BN}+\mathrm{ZrO}_{2}+\mathrm{C} \rightarrow \mathrm{ZrB}_{2}+2 \mathrm{CO} \uparrow+\mathrm{N}_{2} \uparrow
$$

What should be noted is that both reactions (1 and 2) are assisted by gaseous products. As a consequence, the porosity is formed within the outer part of the composite substrate. However, a comparison of LM images (Fig. 8b and e) shows that the extent of the abovementioned structural evolution in much higher in the sample subjected to the step-heating up to $1750{ }^{\circ} \mathrm{C}$ than that after the thermocycling experiment between $1300-1450{ }^{\circ} \mathrm{C}$. In the former case, a depth of SiC-free ZIR characterized by a coexistence of zirconium borides and porosity (Fig. 8c) was $\sim 1700 \mu \mathrm{m}$ (including also the intermediate
Fig. 7 The results of LM and SEM/EDS examinations of the cross-sectioned $\mathrm{Si}-3.2 \mathrm{~B}$ alloy/hBN composite couple after the thermocycling experiment (15 cycles of heating/cooling between $1300-1450{ }^{\circ} \mathrm{C}$ ): a general view of the solidified Si-3.2B alloy (a); a microstructure of solidified drop showing a presence of $\mathrm{Si}+\mathrm{SiB}_{3}$ eutectic features (b); a few $\mathrm{SiC}$ particles formed at the $\mathrm{Si}-3.2 \mathrm{~B}$ alloy/h-BN composite interface (c)
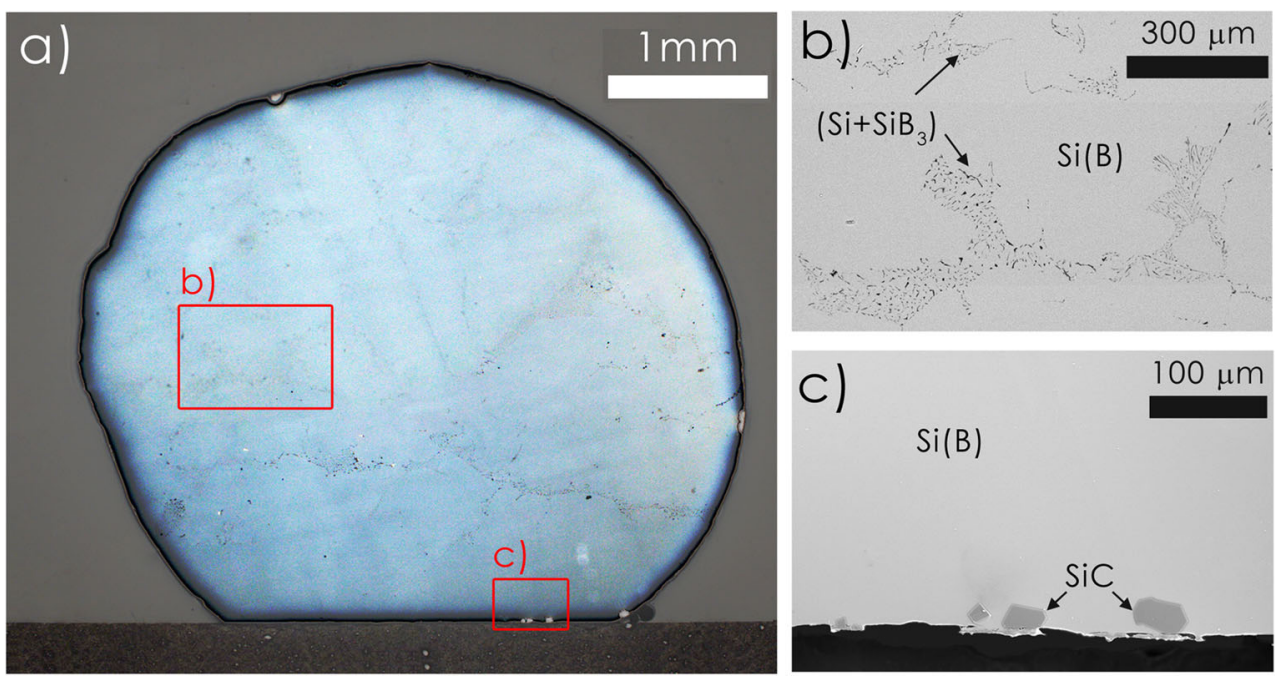
Fig. 8 The results of LM and SEM examinations of the cross-sectioned $\mathrm{Si}-3.2 \mathrm{~B} /(\mathrm{h}-\mathrm{BN}$ $24 \mathrm{ZrO}_{2}-6 \mathrm{SiC}$ ) couples after the high temperature wettability tests: step-heating at temperatures up to $1750{ }^{\circ} \mathrm{C}$ (a-c) and thermocycling between $1300-1450{ }^{\circ} \mathrm{C}(\mathbf{d}-\mathbf{f})$. Please note various magnifications used in (b) and (e)
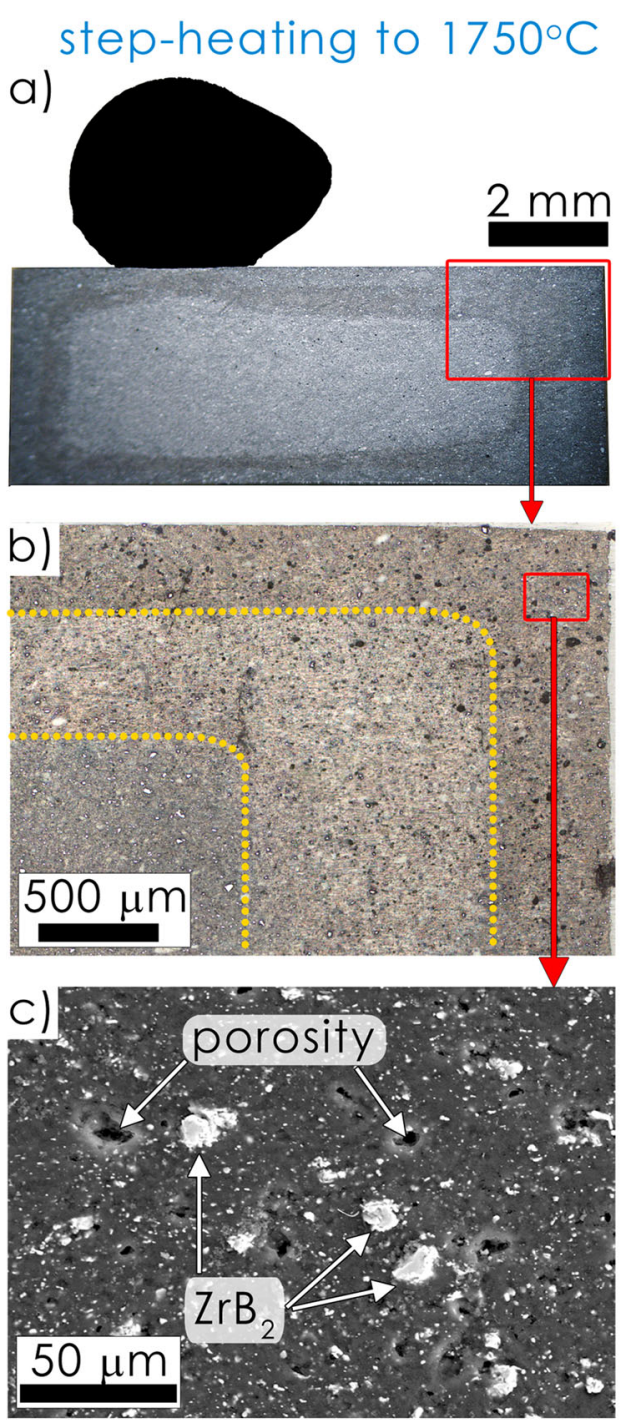

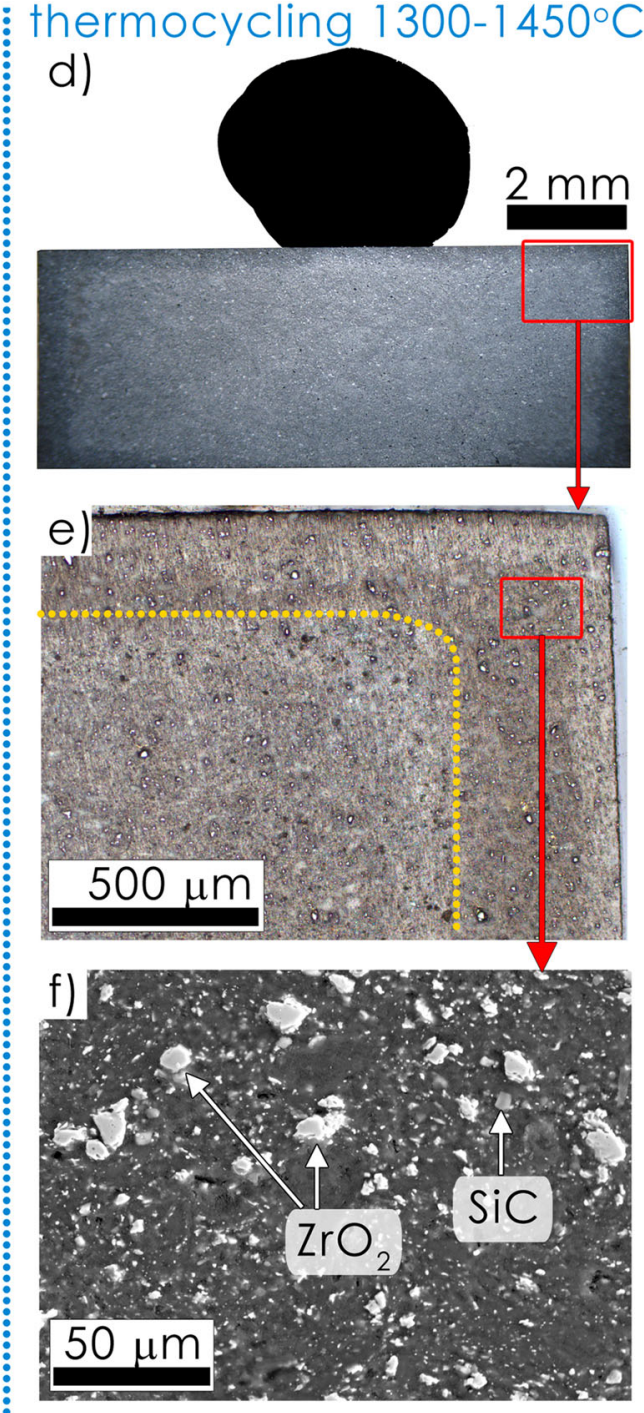

reacted/unreacted area). On the other hand, in the latter one only a degradation of the h-BN matrix (related to the formation of volatile boron oxide) was observed at depth of $\sim 480 \mathrm{~m}$, while the morphology and chemistry of ceramic particles seem to be not strongly affected (Fig. 8f). All phases marked in Fig. 8c and $\mathrm{f}$ where identified based on the results of detailed SEM/EDS and XRD analyses (as in our previous work [16]). Therefore, it is concluded that in order to avoid extensive degradation of the examined h-BN composite, its operational temperature should not exceed $1450{ }^{\circ} \mathrm{C}$ (under conditions used in this study). However, regarding the predicted application in LHTES systems, this temperature limitation still allows using the $\mathrm{h}-\mathrm{BN}-24 \mathrm{ZrO}_{2}-$ $6 \mathrm{SiC}$ composite as the container material for $\mathrm{Si}$ and $\mathrm{Si}-3.2 \mathrm{~B}$ based PCMs, as long as the operating temperature will not be substantially higher than their melting points (1414 and $1385^{\circ} \mathrm{C}$, respectively).

\section{Conclusions}

In this work, the high temperature interaction between the eutectic Si-B alloy and the commercially available h$\mathrm{BN}$ composite was experimentally examined for the first time. Two types of sessile drop experiments were carried out: a step-heating up to $1750{ }^{\circ} \mathrm{C}$, and a thermocycling composed of 15 cycles of melting/solidification of the Si3.2B alloy. Based on the results of performed experiments and structural characterization supported by appropriate data from the literature, the following conclusions are drawn:

1. The Si-3.2B alloy exhibits a lack of wettability with the h-BN composite at temperatures up to $1750^{\circ} \mathrm{C}$. The Si3.2B alloy shows a prominently lower wettability with the h-BN-24ZrO $2-6 \mathrm{SiC}$ composite, than the pure silicon examined under the same testing conditions [15]. 
2. The melting/solidification behavior of the Si-3.2B alloy is characterized by a good repeatability in consecutive thermal cycles and seems to be not affected by interaction with the $\mathrm{h}-\mathrm{BN}$ composite.

3. The interaction between the Si-3.2B alloy and the h- $\mathrm{BN}-24 \mathrm{ZrO}_{2}-6 \mathrm{SiC}$ composite is dominated by a substrate dissolution/reprecipitation mechanism. The mechanism is much more active at higher temperatures, where a discontinuous interfacial product layer made of $\mathrm{SiC}$ and $\mathrm{B}_{4} \mathrm{C}$ is produced.

4. The examined h-BN composite undergoes a structural evolution upon high-temperature experiments applied in this study. When temperature was not higher than $1450{ }^{\circ} \mathrm{C}$ (i.e. during the thermocycling experiment), a degradation of the composite was limited to melting and formation of volatile boron oxide. However, at higher testing temperatures (up to $1750{ }^{\circ} \mathrm{C}$ ) reactions taking place between the composite components leads to a drastic change in the material structure assisted by the formation of porous near surface area. Nevertheless, it still makes it suitable for the predicted Si-B based LHTES system as long as abovementioned temperature restrictions will be kept.

\section{Electronic Supplementary Materials}

The following supplementary materials are available in the online version of this article:

1. Electronic Supplementary Material 1 - the video clip recorded during the sessile drop test of $\mathrm{Si}-3.2 \mathrm{~B} / \mathrm{h}$ $\left.\mathrm{BN}-24 \mathrm{ZrO}_{2}-6 \mathrm{SiC}\right)$ couple performed by the step heating procedure (up to $1750{ }^{\circ} \mathrm{C}$ );

2. Electronic Supplementary Material 2 - the video clip recorded during the sessile drop test of $\mathrm{Si}-3.2 \mathrm{~B} / \mathrm{h}$ $\mathrm{BN}-24 \mathrm{ZrO}{ }_{2}-6 \mathrm{SiC}$ ) couple containing 15 cycles of heating/cooling between (up to $1300-1450{ }^{\circ} \mathrm{C}$ );

3. Electronic Supplementary Material 3 - the video clip showing a full CT scan of the solidified $\mathrm{Si}-3.2 \mathrm{~B} /(\mathrm{h}-\mathrm{BN}-$ $24 \mathrm{ZrO}_{2}-6 \mathrm{SiC}$ ) sessile drop couple subjected to the step heating experiment (up to $1750{ }^{\circ} \mathrm{C}$ ).

Acknowledgements The project AMADEUS has received funds from the European Union's Horizon2020 research and innovation program, FET-OPEN action, under grant agreement 737054 . The sole responsibility for the content of this publication lies with the authors. It does not necessarily reflect the opinion of the European Union. Neither the REA nor the European Commission are responsible for any use that may be made of the information contained therein.

\section{Compliance with Ethical Standards}

Conflict of interests The authors declare that they have no conflict of interest.
Open Access This article is distributed under the terms of the Creative Commons Attribution 4.0 International License (http:// creativecommons.org/licenses/by/4.0/), which permits unrestricted use, distribution, and reproduction in any medium, provided you give appropriate credit to the original author(s) and the source, provide a link to the Creative Commons license, and indicate if changes were made.

\section{References}

1. Zhang N, Yuan Y, Cao X, Du Y, Zhang Z, Gui Y (2018) Latent heat thermal energy storage systems with solid-liquid phase change materials: a review. Adv Eng Mater 20:1700753

2. Cardenas B, Leon N (2013) High temperature latent heat thermal energy storage: phase change materials, design considerations and performance enhancement techniques. Renew Sust Energ Rev 27:724-737

3. Fernandez AI, Barreneche C, Belusko M, Segarra M, Bruno F, Cabeza LF (2017) Considerations for the use of metal alloys as phase change materials for high temperature applications. Sol Energ Mat Sol C 171:275-281

4. Datas A, Cristobal AB, del Canizo C, Antolín E, Beaughon M, Nikolopoulos N, Nikolopoulos A, Zeneli M, Sobczak N, Polkowski W, Tangstad M, Safarian J, Trucchi DM, Bellucci A, Girolami M, Marx R, Bestenlehner D, Lang S, Vitulano A, Sabbatella G, Marti A (2018) AMADEUS: next generation materials and solid state devices for ultra high temperature energy storage and conversion. AIP Conf Proc 2033:170004

5. Datas A, Ramos A, Marti A, del Canizo C, Luque A (2016) Ultra high temperature latent heat energy storage and thermophotovoltaic energy conversion. Energy 107:542-549

6. Datas A, Zeneli M, Del Canizo C, Malgarinos I, Nikolopoulos A, Nikolopoulos N, Karellas S, Marti A (2018) Molten silicon storage of concentrated solar power with integrated thermophotovoltaic energy conversion. AIP Conf Proc 2033:090005

7. Yuan Z, Huang WI, Mukai K (2004) Wettability and reactivity of molten silicon with various substrates. Appl Phys A-Mater 78:617-622

8. Drevet B, Eustathopoulos N (2012) Wetting of ceramics by molten silicon and silicon alloys: a review. J Mater Sci 47:8247-8260

9. Polkowski W, Sobczak N, Nowak R, Kudyba A, Bruzda G, Polkowska A, Homa M, Turalska P, Tangstad M, Safarian J, Moosavi-Khoonsari E, Datas A (2018) Wetting behavior and reactivity of molten silicon with $\mathrm{h}$-BN substrate at ultrahigh temperatures up to $1750{ }^{\circ} \mathrm{C}$. J Mater Eng Perform 27:50405053

10. Polkowski W, Sobczak N, Polkowska A, Kudyba A, Bruzda G, Giuranno D (2019) Silicon as a phase change material: performance of h-BN ceramic during multi-cycle melting/solidification of silicon. JOM 71:1492-1498

11. Polkowski W, Sobczak N, Bruzda G, Nowak R, Giuranno D, Kudyba A, Polkowska A, Pajor K, Kozie T, Kaban I (2019) The effect of boron content on wetting kinetics in Si-B Alloy/h-BN system. J Mater Eng Perform 28:3819-3825

12. Chen L, Wang Y, Shen H, Rao J, Zhou Y (2014) Effect of SiC content on mechanical properties and thermal shock resistance of $\mathrm{BN}-\mathrm{ZrO}_{2}-\mathrm{SiC}$ composites. Mater Sci Eng A 590:346-351

13. Zhang X, Zhang R, Chen G, Han W (2008) Microstructure, mechanical properties and thermal shock resistance of hot-pressed $\mathrm{ZrO}_{2}$ (3Y)-BN composites. Mater Sci Eng A 497:195-199

14. Yang Z, Jia D, Zhou Y, Shi P, Song C, Lin L (2008) Oxidation resistance of hot-pressed SiC-BN composites. Ceram Int 34:317321 
15. http://www.henze-bnp.com/PDF/HeBoSintSinteredBoronNitride Components.pdf, accessed on 14/08/2019

16. Polkowski W, Sobczak N, Polkowska A, Nowak R, Kudyba A, Bruzda G, Giuranno D, Generosi A, Paci B, Trucchi DM (2019) Ultra-high temperature interaction between h-BN-based composite and molten silicon. Metall Mat Trans A Phys Metall Mat Sci 50:997-1008

17. Sobczak N, Nowak R, Radziwill W, Budzioch J, Glenz A (2008) Experimental complex for investigations of high temperature capillarity phenomena. Mater Sci Eng A 495:43-49

18. Olesinski RW, Abbaschian GJ (1984) The B-Si (Boron-Silicon) system. Bull Alloys Phase Diagr, 5

19. Tremblay R, Angers R (1989) Preparation of high purity $\mathrm{SiB}_{4}$ by solid state reaction between $\mathrm{Si}$ and B. Ceram Int 15:73-78
20. Tremblay R, Angers R (1992) Mechanical characterization of dense silicon tetraboride (SiB4). Ceram Int 18:113-117

21. Fahrenholtz WG (2005) The $\mathrm{ZrB}_{2}$ Volatility Diagram. J Am Ceram Soc 88:3509-12

22. Weimer AW (1997). In: Weimer AW (ed) Carbide, nitride and boride materials synthesis and processing. Springer, Netherlands, pp 79-113, https://doi.org/10.1007/978-94-009-0071-4

23. Yan Ch, Liu R, Zhang Ch, Cao Y, Long X (2016) Synthesis of $\mathrm{ZrB}_{2}$ Powders from $\mathrm{ZrO}_{2}$, BN, and C. J Am Ceram Soc 99:16-19

Publisher's Note Springer Nature remains neutral with regard to jurisdictional claims in published maps and institutional affiliations. 